Copyright (C) 2015 by Academic Publishing House Researcher

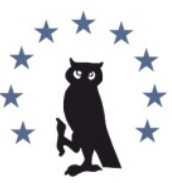

Published in the Russian Federation

European Researcher

Has been issued since 2010 .

ISSN 2219-8229

E-ISSN 2224-0136

Vol. 97, Is. 8, pp. 532-538, 2015

DOI: 10.13187/er.2015.97.532

www.erjournal.ru

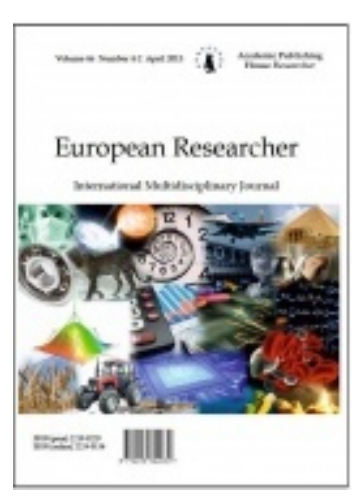

UDC 33

\title{
The Impact Analysis of Sanctions and Embargo on the Russian Foreign Trade Policy
}

\author{
Evgeniya V. Vidishcheva
}

Sochi state university, Russian Federation

26a, Sovetskaya Str., Sochi city, Krasnodar region 354000

$\mathrm{PhD}$ (Economy), Associate Professor

E-mail: evgenia-vv@mail.ru

\section{Abstract}

The article gives an overview of the impact of the sanctions imposed against Russia and Russian retaliatory embargo on the trade policy. Also the article presents the analysis of Russia's foreign trade in recent years in the context of export-import operations, as well as by the main countries and groups of countries, which showed that the volume of trade between Russia and the majority of countries that supported the anti-Russian sanctions were considerably reduced. The main conclusion of the conducted analysis is that before the crisis in Ukraine, our main trading partners were European countries, today a growing share in the trade turnover with Russia began to play the Orient.

Keywords: sanctions, trade, foreign trade policy, export, import substitution.

\section{Введение}

Весною 2014 года Российская Федерация признала выборы о самостоятельности Крыма и Севастополя от Украины и вхождение их в состав России. В ответ на это страны ЕС, Северной Америке и Австралия приняли первый пакет санкции, которые представляли собою ограничение въезда некоторых должностных лиц РФ, а также заморозка их активов в иностранных банках.

В дальнейшем также были приняты второй и третий пакет санкции, но уже по причине дестабилизации ситуации на Украине. Также причиной введения ограничений был тот, факт, что Россия была обвинена в катастрофе самолета, вылетевшего с территории Голландии.

Санкции были распространены на различные секторы в экономике: на торговлю, финансы, промышленность, военную сферу, дипломатию. Влияние всех этих ограничений и ответного эмбарго мы рассмотрим в данной статье.

\section{Обсуждение}

Для данного анализа нам необходимо прибегнуть к цифрам, характеризующим торговую деятельность России на сегодняшний момент и тот же самый показатель годом ранее. 
Общие итоги внешней торговли России в млн. дол.

\begin{tabular}{|l|r|r|r|}
\cline { 2 - 4 } & январь-апрель 2014 & январь-апрель 2015 & темп роста \% \\
\hline Оборот & 265745,6 & 178846,7888 & 67,3 \\
\hline Экспорт & 171116,4 & 122005,9932 & 71,3 \\
\hline Импорт & 94629,1 & 57723,751 & 61 \\
\hline Сальдо & 76487,3 & 64336,4 & - \\
\hline
\end{tabular}

Внешнеторговый оборот Российской Федерации за первые 4 месяца 2015 года составил 179,7 млрд. долл. Если сравнивать с показателем предыдущего года, то оборот снизился на 32,4 \%. Если говорить о сальдо, то оно показывает положительную динамику и составляет 64,3 млрд. долл., что на 12,2 млрд. меньше по сравнению с прошлым годом. Экспорт составил 122 млрд., что на 29 \% меньше прошлогоднего показателя. Можно сделать вывод, что санкции и эмбарго самым прямым образом повлияли на торговую деятельность России. Основные показатели сократились почти на треть, что повлекло за собою определенную нагрузку на ВВП и государственный бюджет [2], [14, 15].

Далее рассмотрим, как обстоят дела с экспортом отдельных продуктов, которые составляют основу всего экспорта Российской Федерации. В их число входят: продовольственные товары и сельскохозяйственное сырье (кроме текстильного), минеральные продукты, топливно-энергетические товары, продукция химической промышленности, кожевенное сырье, пушнина и изделия из них, древесина и целлюлознобумажные изделия.

Рассмотрим экспорт важнейших товаров из России в январе - апреле 2014-2015 годов. Основными товарами, экспортируемые Россией в страны дальнего зарубежья стали топливно-энергетические товары, доля которых занимала $68 \%$ от всего экспорта. Прошлогодний показатель равнялся 75,6 \%.

Стоимостный объем этих товаров также подвергся изменению - он снизился на 35 \%, а вот физический увеличился на 10,3 \%. В том числе, экспорт нефти увеличился на $10 \%$, электроэнергия на 40 \%, нефтепродукты - $27 \%$.

Доля металлов в структуре экспорта составила почти 10\%, прошлогодний показатель равнялся 7 \%. Стоимость упала на о,6 \%, физический объем вырос на $13 \%$.

Химическая промышленность показала положительную динамику - если в прошлом году ее доля в экспорте равнялась 4,9 \%, то уже в январе-апреле 2015 цифра равнялась 6,4 \%. Стоимость упала на 5,9 \%, а вот физический увеличился на 8,7 \%.

Теперь рассмотрим, как обстоят дела с импортом важнейших товаров на территорию РФ 2014- 2015 гг.

Импорт России в январе-апреле 2015 года составил 57,7 млрд. долл. США и по сравнению с январем-апрелем 2014 года снизился на 39,о \%. Основную доля в импорте РФ составили машины и оборудования. На них за первые четыре месяца приходилось порядка 48 \%, в прошлом году эта цифра равнялась 50 \%. Стоимостный объем упал на 40 \%.

Химическая промышленность в импорте составила 19 \%, за январь-апрель 2015 16,4 \%. Стоимостный объем ввоза продукции химической промышленности снизился по сравнению с январем-апрелем 2014 года на 28,9 \%, а физический объем - на 13,2 \%. При этом физические объемы поставок косметических средств снизились на 13,0 \%, пластмасс и изделий из них - на 26,5 \%, каучука, резины и изделий из них - на 27,5 \%.

Доля продовольствия в структуре импорта составила 13,8 \% (2014 - 14,5 \%). Что касается объёмов стоимостных и физических, то они сократились по сравнению с предыдущим годом на 40 \% и 26 \% соответственно.

Рассмотрим внешнюю торговлю Российской Федерации по основным странам и группам стран. 
В страновой структуре внешней торговли России ведущее место занимает Европейский Союз, как крупнейший экономический партнер страны. На долю Европейского Союза в январе-апреле 2015 года приходилось 45,7 \% российского товарооборота (в январе-апреле 2014 года - 49,5 \%), на страны СНГ - 11,8 \% (13,1 \%), на страны ЕАЭС - 7,1 \% (6,6 \%), на страны АТЭС - 27,9\%(25,7\%).

Основными торговыми партнерами России в январе-апреле 2015 года среди стран дальнего зарубежья были: Китай, товарооборот с которым составил 20,6 млрд. долл. США (70,6 \% к январю-марту 2014 года), Германия - 15,4 млрд. долл. США (64,8 \%), Нидерланды - 15,0 млрд. долл. США (62,3 \%), Италия - 11,6 млрд. долл. США (71,5 \%), Турция - 9,о млрд. долл. США (84,5 \%), Япония - 8,2 млрд. долл. США (79,4 \%), США - 7,1 млрд .долл. США (79,8 \%), Республика Корея - 6,0 млрд. долл. США (72,1 \%), Польша - 4,5 млрд. долл. США (52,9 \%), Франция - 3,8 млрд. долл. США (56,8 \%) [1, 2, 4, 5, 7].

На все эти изменения также повлияли темпы роста мировой торговли. Она сегодня переживает не лучшие времена. ВТО ухудшила прогнозы по мировой торговле.

Мировая торговля после кризиса восстанавливается слишком медленно. К такому выводу пришли эксперты Всемирной торговой организации (ВТО), которые ухудшили прогнозы на 2015 и 2016 годы.

В 2014 оборот мировой торговли в третий раз подряд оказался ниже 3 \% (2,8 \%), в текущем году, полагает ВТО, темпы ускорятся до 3,3 \%, а в будущем - до 4 \%. Но в сентябре организация считала, что показатель возьмет барьер в 4 \% уже в этом году.

Слабую динамику внешней торговли ВТО объясняет тем, что в развивающихся странах темпы экономического подъема слишком низкие, а в развитых рост неравномерный. Кроме того, на торговлю оказывают влияние геополитические факторы.

И на первых порах негативное влияние эмбарго на розничные цены проявлялось слабо.

Во-первых, контрсанкции были введены в августе, когда сезонное снижение цен смогло нейтрализовать или смягчить подорожание продуктов из-за эмбарго. Во-вторых, российские поставщики накопили довольно большие запасы продуктов, их дефицит стал ощущаться не сразу. В-третьих, когда запасы стали подходить к концу, многие поставщики успели наладить поставки из тех стран, на которые эмбарго не распространялось.

Наконец, некоторые смогли организовать поставки продукции через третьи государства, где нелегально или полулегально переоформлялась страна происхождения данных товаров. Главным транзитным узлом для таких операций стала Белоруссия, другими центрами переоформления страны происхождения стали Фарерские острова и Гренландия (для рыбы из Норвегии), Сербия и Турция (для плодоовощной продукции). Добавление новых посредников увеличивало стоимость товаров, но такие схемы позволили смягчить их дефицит.

Больше всего пострадали от вызванного контрсанкциями роста цен потребители в Калининградской области. Этот регион к моменту введения эмбарго на 70 \% зависел от импорта молочной продукции, на 50 \% - от поставок фруктов и овощей и на $40 \%$ - от импорта мяса птицы из стран ЕС. И там уже вскоре после введения антисанкций цены на некоторые продукты выросли в 1,5-2 раза. Местные власти и поставщики возлагали большие надежды на замещение продукции из стран ЕС белорусскими товарами, но поставщики из Белоруссии во многих случаях также резко увеличили закупочные цены. Но проблемы со снабжением региона отчасти смягчила «серая» торговля, о которой еще пойдет речь далее [10].

Российские компании сумели заменить большую часть продукции из США и Евросоюза, на ввоз которой было наложено эмбарго. Проблемными категориями оказались некоторые виды сыров, рыбы и морепродуктов. Но даже на замещенные продукты цены продолжают расти.

Импорт молочной продукции снизился на $57 \%$, свинины - на 45 \%, овощей - на 44 \%, мяса птицы - на 39 \%. Единственный товар из санкционного списка, показавший рост поставок, - говядина: в августе ее было ввезено на 47 \% больше.

Опрошенные ретейлеры и рестораторы утверждают, что сумели наполнить полки и меню аналогами большей части утраченных товарных позиций. «Большинство товаров нам удалось заменить либо российскими аналогами, либо продукцией из стран, импорт из 
которых разрешен», - рассказывает представитель сети гипермаркетов Metro C\&C Оксана Токарева. В сети «О’кей» не заметили значительного сужения ассортимента, потому что и ранее работали в основном с российскими поставщиками и дистрибьюторами, говорит ее представитель Артем Глущенко. X5 Retail Group (сети «Перекресток», «Пятерочка», «Карусель» и др.) и «Дикси» (сети «Дикси», «Виктория» и др.) также нашли альтернативные товары [11].

Меньше всего проблем оказалось с замещением продуктов из так называемого борщевого набора: картофеля, лука, моркови, капусты, свеклы, а также сезонными яблоками, цитрусовыми, бахчевыми. «Отечественный урожай хороший, и цены даже немного снижаются, - утверждает руководитель управления по связям с общественностью $\mathrm{X}_{5}$ Владимир Русанов. - В среднесрочной перспективе томаты и огурцы также будут доступны в достаточном количестве». Х5 выкладывает отечественную сливу, плюс закупает ее в Сербии, гранат и рукколу в ее распределительные центры везут из Израиля, виноград импортируется из Турции, персики - из Грузии, яблоки «Гала» - из Азербайджана. «О'кей» заключила договор на прямые поставки овощей и фруктов из Турции и сейчас ведет переговоры с израильскими, иранскими и марокканскими производителями. «Дикси» также увеличивает загрузку российских партнеров - из Кубани и Ставропольского края. А экзотические фрукты будет заказывать из стран Азии, Латинской Америки и Африки.

Импортную молочную продукцию, кроме сыров, в российских магазинах почти полностью заместили российские производители. К примеру, «Дикси» заменила финскую и литовскую сметану российской. В этой категории, как отмечают представители торговых компаний, отечественный производитель конкурентоспособен.

Минусом таких замен стал массовый пересмотр прайс-листов. Практически все молочные поставщики предупреждают о повышении закупочных цен на 7-10 \%, мотивируя это ослаблением рубля и ростом цен на сырье.

Также, несмотря на то, что Россия почти полностью обеспечивала себя мясом птицы, именно курятина оказалась лидером в росте цен: с начала года, по данным Росстата, она прибавила в стоимости 13,8 \%. Ретейлеры объясняют это возникшим в начале года дефицитом другого продукта - свиного шпига: чтобы компенсировать дефицит сырья, производители колбас и сосисок начали закупать курятину.

Крупнейшие производители свинины также заявляют о повышении расценок на 8-10\%. Премиальную говядину удалось заменить без проблем: в «О'кей» уже продается мясо из Южной Америки, Новой Зеландии и Уругвая. В Metro завезли премиальную говядину из Аргентины и Новой Зеландии.

Сложнее всего, оказалось, заместить импортные сыры: пока в магазинах остается некоторое количество попавших под эмбарго европейских брендов на стоках, но через несколько недель из разряда «элитных» останутся только швейцарские сыры. В гипермаркетах Globus, по словам представителя компании Натальи Рычковой, восполнить европейские сыры удалось лишь на 10\%. Сложно найти аналоги сырам Франции (камамбер, бри), итальянским рассольным и свежим сырам, а также овечьим и козьим испанским. Globus продолжает искать замену твердым сырам - маасдаму и пармезану. В «Дикси» рассказывают, что нашли замену европейскому маасдаму в Израиле - сейчас он проходит сертификацию [11].

Нельзя не затронуть политическую составляющую в этом вопросе. Как известно США является главным инициатором введения санкции на российскую сторону. Но давайте проследим, как обстоят дела в торговой деятельности между двумя государствами.

Введенные против России санкции не привели к снижению объемов внешнеторгового оборота с США и это убедительно доказывает, что при введении санкций власти США действовали исключительно в своих интересах, заявил вице-премьер Аркадий Дворкович. «Следует помнить, что каждый действует в своих интересах», - заключил российский вицепремьер [9].

По итогам 2014 года объемы торговли России с большинством стран, поддержавших антироссийские санкции, заметно сократились. Так, например, показатели товарооборота с Португалией упали, по данным Федеральной таможенной службы (ФТС), на 41,2 \%, с Грецией — на 39,2 \%, с Венгрией — на 27,5 \%, с Великобританией - на 21,3 \%, с Литвой —на $20,5 \%$. 
Товарооборот с другими странами ЕС снижался медленнее. Так, например, объемы торговли с Польшей сократились на 17,6 \%, с Францией - на 17,5 \%, с Финляндией - на $14,7 \%$, с Италией - на 10 \%, с Германией - на 6,5 \%. Сократились, хотя и не так заметно, объемы торговли России и с другими странами, объявившими о введении против нее санкций. В частности, объемы торговли с Канадой уменьшились на 3 \%, с Японией - на 7,3\%, с Норвегией - на 18,5\%.

Одной из немногих стран, чья торговля с Россией на фоне санкций только выросла, стали США. По итогам 2014 года объем российско-американской торговли увеличился, по данным ФТС, на 5,6 \% и составил около 29,2 млрд. долл. При этом объемы импорта американских товаров в Россию выросли сразу на 12,1 \% - до 18,5 млрд. долл. Доля США во внешнеторговом обороте России выросла в 2014 года с 3,3 \% до 3,7 \% [5], [12,13].

При этом особенно сильно сократился импорт продовольственных товаров. В частности, зарубежные закупки молочных продуктов сократились в 5,6 раза, рыбы - в три раза, сахара - в 2,9 раза, мяса - в 2,3 раза, фруктов - на $90 \%$, а овощей - на $70 \%$. В целом импорт продовольствия в Россию уменьшился на 44,3 \% [1].

\section{Заключение}

В заключение следует отметить, что:

- Если до кризиса на Украине нашими главными торговыми партнерами были страны Европы, то на сегодня все большую долю в торговом обороте с Россией стали играть страны Востока;

- Наилучшие торговые показатели были в 2012-2013 годах. В это время торговый оборот между странами Европы и России достиг максимальных результатов;

- Россия так и остается на «нефтяной игле». Доля нефти в экспорте РФ составляет 30 \%. А если говорить об остальных минеральных ресурсах, то эта величина составляет около $70 \%$;

- Наибольшую долю в структуре импорта занимают: продовольственные товары, машины и оборудования, а также лекарственные препараты;

- В 2014 году Россией были приняты ряд меры для обеспечения экономической безопасности страны. На сегодняшний день полным ходом идет политика импортозамещения сельскохозяйственной продукции.

\section{Примечания:}

1. Отчет импорта и экспорта товаров в Россию, ФТС 2014 [Электронный ресурс]. Режим доступа: http://www.customs.ru/ index.php?id=13858\&Itemid= 2095\&option= com_content\&view=article (Дата обращения: 25.06.15).

2. Отчет ФТС о внешнеторговой деятельности России за январь - апрель 2015 года [Электронный ресурс]. Режим доступа: http://www.customs.ru/index.php?id=13858\&Itemid =2095\&option=com_content\&view=article (Дата обращения: 25.06.15).

3. Указ о применении отдельных специальных экономических мер в целях обеспечения безопасности Российской Федерации от 6 августа 2014 года [Электронный peсурс]. Режим доступа: http://kremlin.ru/events/president/news/46404/ (Дата обращения: 25.06.15).

4. Доклад Министерства экономического развития - Торгово-экономическое сотрудничество между Российской Федерацией и Японией [Электронный ресурс]. Режим доступа http://www.ved.gov.ru/exportcountries/jp/jp_ru_relations/jp_ru_trade/ (Дата обращения: 01.06.2015).

5. Доклад Министерства экономического развития - Внешняя торговля России с США [Электронный ресурс]. Режим доступа http://www.ved.gov.ru/ exportcountries/us/ us_ru_relations/us_ru_trade/ (Дата обращения: 01.06.2015).

6. Доклад Министерства экономического развития - Внешняя торговля России с Австралией [Электронный ресурс]. Режим доступа http://www.ved.gov.ru/files/images/ country/Australia/Foreign (Дата обращения: 1.06.2015). 
7. Доклад Министерства экономического развития - Импорт России из США [Электронный ресурс]. Режим доступа http://www.ved.gov.ru/importcountries/us/ us_ru_relations/us_ru_trade/ (Дата обращения: 1.06.2015).

8. Реакция Запада на российское эмбарго: производители продуктов понесут убытки, но больше всего пострадает РФ. [Электронный ресурс]. Режим доступа: http://www.newsru.com/world (Дата обращения: 25.06.15).

9. Россия избежала снижения товарооборота с США вопреки санкциям. [Электронный pecypc]. Режим доступа: http://top.rbc.ru/ economics/ 14/ 04/2015/ 552d0fd49a794720d2d765bc (Дата обращения: 25.06.15).

10. Что стало с приграничными районами России после антисанкций. [Электронный pecypc]. Режим доступа: http://pda.rbcdaily.ru/2015/o4/22/economy (Дата обращения: 25.06.15).

11. Ретейлеры и рестораны нашли альтернативу только части запрещенного импорта. [Электронный peсурс]. Режим доступа: http://rbcdaily.ru/market/562949992433218 (Дата обращения: 25.06.15).

12. Импорт продовольственных товаров в марте 2015 года сократился на 38,8 \% [Электронный pecypc]. Режим доступа: http://1prime.ru/consumer_markets/ 20150407/806916286.html (Дата обращения: 28.07.15).

13. Россия сократила импорт продуктов [Электронный ресурс]. Режим доступа: http:// www.dp.ru/a/2015/o5/29/Rossija_sokratila_import_p/ (Дата обращения: 28.07.15).

14. Доклад об экономике России. Всемирный банк, апрель 2015 [Электронный ресурс]. Режим доступа: http:// www.worldbank.org/content/dam/ Worldbank/ document/ eca/russia/ rer33-rus.pdf (Дата обращения: 28.07.15).

15. Санкции Запада против России [Электронный ресурс]. Режим доступа: http://www.rg.ru/sujet/2861/ (Дата обращения: 28.07.15).

\section{References:}

1. Otchet importa i eksporta tovarov v Rossiyu, FTS 2014 [Elektronnyi resurs]. Rezhim dostupa: http://www.customs.ru/ index.php?id=13858\&Itemid= 2095\&option=com content\&view=article (Data obrashcheniya: 25.06.15).

2. Otchet FTS o vneshnetorgovoi deyatel'nosti Rossii za yanvar' - aprel' 2015 goda [Elektronnyi resurs]. Rezhim dostupa: http:// www.customs.ru/index.php?id=13858\&Itemid =2095\&option=com_content\&view=article (Data obrashcheniya: 25.06.15).

3. Ukaz o primenenii otdel'nykh spetsial'nykh ekonomicheskikh mer $\mathrm{v}$ tselyakh obespecheniya bezopasnosti Rossiiskoi Federatsii ot 6 avgusta 2014 goda [Elektronnyi resurs]. Rezhim dostupa: http://kremlin.ru/ events/president/news/46404/ (Data obrashcheniya: 25.06.15).

4. Doklad Ministerstva ekonomicheskogo razvitiya - Torgovo-ekonomicheskoe sotrudnichestvo mezhdu Rossiiskoi Federatsiei i Yaponiei [Elektronnyi resurs]. Rezhim dostupa http:// www.ved.gov.ru/ exportcountries/jp/jp_ru_relations/jp_ru_trade/ (Data obrashcheniya: 01.06.2015).

5. Doklad Ministerstva ekonomicheskogo razvitiya - Vneshnyaya torgovlya Rossii s SShA [Elektronnyi resurs]. Rezhim dostupa http:// www.ved.gov.ru/ exportcountries/us/ us_ru_ relations/ us_ru_trade/ (Data obrashcheniya: 01.06.2015).

6. Dōklā $\bar{d}$ Ministerstva ekonomicheskogo razvitiya - Vneshnyaya torgovlya Rossii s Avstraliei [Elektronnyi resurs]. Rezhim dostupa http://www.ved.gov.ru/files/images/ country/ Australia/ Foreign (Data obrashcheniya: 1.06.2015).

7. Doklad Ministerstva ekonomicheskogo razvitiya - Import Rossii iz SShA [Elektronnyi resurs]. Rezhim dostupa http://www.ved.gov.ru/importcountries/us/ us_ru_relations/ us_ru_trade/ (Data obrashcheniya: 1.06.2015).

8. Reaktsiya Zapada na rossiiskoe embargo: proizvoditeli produktov ponesut ubytki, no bol'she vsego postradaet RF. [Elektronnyi resurs]. Rezhim dostupa: http://www.newsru. com/ world (Data obrashcheniya: 25.06.15).

9. Rossiya izbezhala snizheniya tovarooborota s SShA vopreki sanktsiyam. [Elektronnyi resurs]. Rezhim dostupa: http://top.rbc.ru/economics/ 14/ 04/2015/ 552d0fd49a794720d2d765bc (Data obrashcheniya: 25.06.15). 
10. Chto stalo s prigranichnymi raionami Rossii posle antisanktsii. [Elektronnyi resurs]. Rezhim dostupa: http://pda.rbcdaily.ru/ 2015/ 04/ 22/ economy (Data obrashcheniya: 25.06.15).

11. Reteilery i restorany nashli al'ternativu tol'ko chasti zapreshchennogo importa. [Elektronnyi resurs]. Rezhim dostupa: http://rbcdaily.ru/market/562949992433218 (Data obrashcheniya: 25.06.15).

12. Import prodovol'stvennykh tovarov $\mathrm{v}$ marte 2015 goda sokratilsya na 38,8 \% [Elektronnyi resurs]. Rezhim dostupa: http://1prime.ru/consumer_markets/ 20150407/ 806916286.html (Data obrashcheniya: 28.07.15).

13. Rossiya sokratila import produktov [Elektronnyi resurs]. Rezhim dostupa: http:// www.dp.ru/a/2015/ 05/29/Rossija_sokratila import_p/ (Data obrashcheniya: 28.07.15).

14. Doklad ob ekonomike Rossii. Vsemirnyi bank, aprel' 2015 [Elektronnyi resurs]. Rezhim dostupa: http://www.worldbank.org/content/dam/ Worldbank/ document/ eca/russia/rer33rus.pdf (Data obrashcheniya: 28.07.15).

15. Sanktsii Zapada protiv Rossii [Elektronnyi resurs]. Rezhim dostupa: http:// www.rg.ru/ sujet/2861/ (Data obrashcheniya: 28.07.15).

УДК 33

\section{Анализ влияния санкций и эмбарго на внешнеторговую политику России}

\section{Евгения Владимировна Видищева}

Сочинский государственный университет, Российская Федерация

354000, г. Сочи, ул. Советская, 26 а

Кандидат экономических наук, доцент

E-mail: evgenia-vv@mail.ru

Аннотация. В статье дается обзор влияния введенных против России санкций и ответного эмбарго на российскую внешнеторговую политику. Также представлен анализ внешнеторгового оборота России за последнее время в разрезе экспортно-импортных операций, а также по основным странам и группам стран, который показал, что объемы торговли России с большинством стран, поддержавших антироссийские санкции, заметно сократились. Основным выводом проведенного анализа является то, что до кризиса на Украине нашими главными торговыми партнерами были страны Европы, то на сегодня все большую долю в торговом обороте с Россией стали играть страны Востока.

Ключевые слова: санкции, торговля, внешнеторговая политика, экспорт, импорт, замещение. 